\title{
Análisis filosófico: Strawson entre Wittgenstein y Quine*
}

\author{
LIZA SKIDELSKY \\ Departamento de Filosofía \\ Universidad de Buenos Aires \\ lskidels@filo.uba.ar
}

\begin{abstract}
Resumen: En Análisis y metafísica, Strawson da razones por las cuales ciertos rasgos del análisis terapéutico y de la concepción quineana constituyen una amenaza para la tarea del análisis conectivo. Las razones en contra del primero son que posee un "espíritu negativo" y es "asistemático", mientras que la razón en contra de la segunda es su reduccionismo ontológico. Mi intención es mostrar que estos rasgos no conllevan un peligro una vez que las concepciones de Wittgenstein y Quine se entienden de manera menos fuerte que como las entiende Strawson. Por un lado, intento mostrar que el espíritu negativo es una cuestión de actitud que no influye significativamente en el resultado del análisis que es el mismo que el del análisis conectivo; y que el análisis terapéutico es compatible con la sistematicidad. Por otro lado, intento mostrar que dado que el naturalismo quineano de la continuidad entre la filosofía y la ciencia no deja de lado el sentido común, no constituye una amenaza para el análisis conectivo.
\end{abstract}

Palabras clave: análisis conectivo, análisis terapéutico, naturalismo, reduccionismo ontológico

Según Strawson, la tarea principal de la filosofía consiste en "lograr una visión clara de nuestros conceptos y su lugar en nuestras vidas" (1998a, p. 20), para ello hay que responder a la pregunta por los conceptos "más generales en términos de los cuales organizamos nuestro pensamiento, nuestra experiencia del mundo" y "cómo se relacionan unos con otros en el interior de la estructura total de nuestro pensamiento" (1997a, pp. 79-80). Esta concepción de la filosofía tiene su expresión metodológica en lo que Strawson denomina 'análisis conectivo'. En Análisis y metafísica, Strawson da razones por las cuales ciertos rasgos de la concepción terapéutica de Wittgenstein y de la ontología quineana constituyen una amenaza para la tarea del análisis conectivo (y es, justamente, este sentido de amenaza el que rescata el título de este trabajo). Las razones que da en contra del análisis terapéutico son que posee un "espíritu negativo" y es "asistemático", mientras que la razón en contra de la concepción filosófica quineana es su "reduccionismo ontológico".

*Agradezco a Diana Pérez y Julia Vergara por la lectura de una versión anterior de este trabajo, al evaluador o evaluadora anónimo(a) de esta revista por sus valiosos comentarios, y en especial a Samuel Cabanchik, cuyas iluminadoras sugerencias me permitieron encarar las cuestiones que trato en este trabajo desde una perspectiva mucho más profunda y fructífera. 
El objetivo de este trabajo consiste en mostrar que estos rasgos del análisis terapéutico y de la concepción quineana no conllevan un peligro para el desarrollo del análisis conectivo. Para ello, por un lado, intentaré mostrar que las razones aducidas se debilitan una vez que las concepciones de Wittgenstein y Quine, con respecto a los rasgos mencionados, se entienden de manera menos fuerte que como las entiende Strawson; y por el otro (y relacionado con lo anterior), intentaré mostrar que si bien el análisis conectivo responde a cierta concepción de la filosofía (que denominaré tesis metafilosóficas strawsonianas), es compatible con otras tesis metafilosóficas (en este caso, las de las concepciones wittgensteiniana y quineana).

Mi objetivo es modesto. Quisiera marcar las diferencias con otros dos objetivos que no voy a perseguir aquí y que son más ambiciosos. No me voy a ocupar de realizar una comparación, estableciendo semejanzas y diferencias, entre las metodologías de los tres filosófos en cuestión, porque mi objetivo es tan sólo mostrar que algunas de esas diferencias (las que se han mencionado antes) no constituyen una amenaza para el desarrollo del análisis conectivo. En conexión con esto, mi objetivo tampoco consiste en mostrar que las razones que da Strawson no son buenas razones para distinguir su análisis de los de Wittgenstein y Quine. Para mostrar que algo no constituye un peligro para otra cosa no hace falta mostrar que son lo mismo, sólo hace falta mostrar que aquellos rasgos de una cosa que en principio parecen peligrosos no lo son, y esto se puede hacer manteniendo la idea de que esos mismos rasgos ( $u$ otros no considerados) son distintos de los de la cosa amenazada. Mutatis mutandi para el caso del análisis conectivo y aquellos rasgos del análisis terapéutico y de la ontología quineana que constituirían una amenaza para el primero. Así, del hecho de que las razones que da Strawson no sean buenas razones para sostener que hay una amenaza para el análisis conectivo, no se sigue la conclusión fuerte de que el análisis conectivo no se diferencia del análisis terapéutico ni del reduccionismo quineano.

En la primera parte del trabajo reconstruiré la concepción conectiva de la filosofía sostenida por Strawson. Distinguiré las tesis metafilosóficas, las filosóficas y las sucesivas especificaciones de su metodología. En la segunda parte, desarrollaré la concepción terapéutica de Wittgenstein e intentaré mostrar, por un lado, que su "espíritu negativo" es una cuestión de actitud que no influye significativamente en el resultado del análisis, el cual es compatible con el resultado del análisis conectivo; y, por el otro, que el análisis terapéutico es compatible con la sistematicidad (por supuesto, dado mi objetivo moderado, esto no muestra, ni es mi intención hacerlo, que el análisis terapéutico queda asimilado al conectivo o viceversa). En la tercera parte expondré la concepción quineana de la filosofía e intentaré mostrar que el hecho de que el naturalismo quineano de la continuidad entre la filosofía y la ciencia no deje de lado el sentido común permite 
afirmar que su naturalismo no es un peligro para el análisis conectivo (por supuesto, dado mi objetivo moderado, esto no muestra, ni es mi intención hacerlo, que los naturalismos de Quine y Strawson son indistinguibles). Finalmente, retomo los puntos fundamentales de las secciones anteriores para establecer las conclusiones.

\section{La concepción conectiva de la filosofía}

Antes de desarrollar el análisis conectivo quisiera detenerme en los objetivos, intereses y motivaciones que llevan a Strawson a sostener este método y que pueden agruparse en ciertas tesis metafilosóficas. Se ha mencionado que la respuesta a la pregunta por los conceptos en términos de los cuales organizamos nuestro pensamiento y nuestra experiencia acerca del mundo, y las relaciones entre ellos, constituye la tarea de la filosofía. La filosofía es así concebida como una tarea de análisis conceptual, a priori, cuyo objetivo es la clarificación de nuestros conceptos ordinarios. Strawson parte del análisis del lenguaje ordinario porque cree que éste tiene todos los recursos necesarios para satisfacer nuestras necesidades tanto de comprensión ordinaria como filosófica. En este sentido se opone a todo tipo de análisis que consista en la construcción de lenguajes formales o regimentados, o de paráfrasis (que utilizan el aparato lógico) a partir del lenguaje natural puesto que un lenguaje así sacrificaría gran parte de los significados ordinarios. La motivación básica de esta distinción es que la tarea filosófica consiste en la descripción del patrón complejo que exhiben los conceptos cotidianos y no en la prescripción de usos lingüísticos. Así, la filosofía tiene como instrumento el análisis del lenguaje natural, que es el que revela la estructura conceptual que subyace a nuestra comprensión del mundo. En cambio, los lenguajes regimentados, como el de la ciencia, si bien revelan aspectos de la concepción del mundo, son lenguajes cuyos conceptos dependen de los conceptos cotidianos, los cuales son considerados básicos desde el punto de vista de su posesión. En este sentido, la filosofía cuya tarea es el establecimiento de conexiones entre estos conceptos básicos es considerada prioritaria o anterior desde el punto de vista conceptual. ${ }^{1}$

Esta concepción de la filosofía se refleja en la adopción de una posición, al menos, con respecto a dos puntos de vista metafilosóficos: (i) la relación entre filosofía y ciencia, y (ii) la oposición entre el lenguaje ordinario y el lenguaje regimentado. Así, las tesis metafilosóficas strawsonianas que subyacen al método del análisis conectivo pueden resumirse de la siguiente manera: (i') la tarea de la filosofía es puramente conceptual y consiste en la clarificación de nuestros conceptos ordinarios. El uso de conceptos científicos supone la posesión de conceptos ordinarios. En este sentido,

\footnotetext{
${ }^{1}$ Esta concepción de la filosofía se desarrolla, en particular, en Strawson 1967 y 1985.
} 
hay una dependencia conceptual de la ciencia con respecto a la filosofía. $\left(i^{\prime}\right)$ está estrechamente relacionada con (ii'): el lenguaje ordinario tiene todos los recursos necesarios para satisfacer tanto nuestras necesidades de comprensión ordinaria como filosófica. Por eso, la filosofía se ocupa de la clarificación conceptual del lenguaje ordinario (a diferencia de la construcción de lenguajes regimentados).

Si tuvieramos que resaltar el interés o la motivación básica de la filosofía strawsoniana, diríamos que el alma de su filosofía es la distinción entre la referencia y la predicación. ${ }^{2}$ Dada la tarea de clarificación conceptual, y puesto que los conceptos tienen su lugar en la proposición y es la lógica la que estudia las formas generales de la proposición, es ésta el punto de partida de la investigación. La forma más simple de proposición es la atómica, cuya estructura manifiesta una dualidad fundamental, una distinción básica entre expresiones referenciales y expresiones predicativas. Para establecer el papel que estos conceptos lógicos desempeñan en nuestro esquema conceptual, según Strawson, se requiere un enfoque ontológicoepistemológico. Así, desde el punto de vista ontológico y en la base de la dualidad lógica se encuentra una dualidad metafísica entre particulares y universales; y desde el punto de vista epistemológico, hay una dualidad entre objetos perceptuales y conceptos. Esta distinción lógica y sus conexiones con las dualidades ontológicas y epistemológicas constituyen los rasgos fundamentales de nuestro esquema conceptual. ${ }^{3} \mathrm{El}$ análisis conectivo es el método que utiliza Strawson para establecer estos rasgos fundamentales de nuestro pensamiento acerca de la realidad y para especificar las conexiones entre ellos (esto es, lo descrito anteriormente es el resultado particular — la filosofía- al que llega Strawson al aplicar su método).

Hay varias maneras en las que Strawson formula el método de la filosofía. Estas maneras, en mi opinión, no sólo constituyen distintas especificaciones de un mismo método, sino que también se construyen en oposición a otras concepciones de la filosofía. En primer lugar, en Individuals, Strawson lo denomina metafísica descriptiva en oposición a la metafísica revisionista. ${ }^{4}$ Una segunda especificación es la que realiza en Análisis y metafísica (cap. 1), denominándolo concepción gramatical del análisis filosófico en oposición a la concepción terapéutica (Wittgenstein). Finalmente, también

${ }^{2}$ Cfr. Tse 1998, p. 373, y la respuesta de Strawson 1998b, p. 383.

${ }^{3} \mathrm{El}$ resto de los conceptos básicos de los cuales Strawson se ha ocupado están relacionados con estas dualidades fundamentales en los tres ámbitos mencionados. Por ejemplo, los conceptos de verdad y sentido, entre otros, están relacionados con la dualidad lógica; los de espacio, tiempo y objeto, entre otros, están relacionados con la dualidad ontológica, y el de causalidad está relacionado con la dualidad epistemológica. Véanse los artículos compilados en Strawson 1983 para lo primero, Strawson 1959 para lo segundo y Strawson 1997a, cap. 5, entre otros, para lo tercero.

${ }^{4}$ Sólo menciono aquellos textos en los que se desarrollan con más extensión estas especificaciones. 
en Análisis y metafísica (cap. 2), lo denomina modelo de la conexión o análisis conectivo, en oposición al análisis reductivo (Quine).$^{5}$ A continuación se verá en qué consisten las distintas especificaciones de su método.

En primer lugar, en la introducción de Individuals, Strawson hace una distinción entre metafísica descriptiva y metafísica revisionista. La primera se ocupa de "describir la estructura real de nuestro pensamiento acerca del mundo", mientras que la segunda se ocupa de "producir una estructura mejor" (p. 9). Strawson se inscribe en la tradición aristotélico-kantiana de descripción de los rasgos más generales de nuestro esquema conceptual en contraposición a la tradición de los grandes sistemas filosóficos en los cuales se trata de ofrecer un nuevo enfoque de la realidad. Así, la filosofía analítica "no promete ninguna visión reveladora" (1997a, p. 44), sino que trata de descubrir los rasgos fundamentales de nuestra manera de pensar acerca de la realidad. Estos rasgos fundamentales de nuestro esquema conceptual se encuentran en un núcleo de conceptos que son universales (en el sentido de ser compartidos por toda la especie humana) y ahistóricos o inmutables; y la tarea de la metafísica es describir sus interconexiones.

La metafísica descriptiva parece comportar una leve diferencia en alcance con el análisis conceptual. Hay un sentido, el más importante, en que ambas se ocupan de establecer conexiones entre los términos del lenguaje o del esquema conceptual; sin embargo, la tarea de la metafísica descriptiva parece ser más ambiciosa que la del análisis conceptual. Estudiar los rasgos del pensamiento acerca del mundo es una tarea mucho más general que cualquier análisis conceptual, que siempre tiene un alcance parcial y limitado. A pesar de esta leve diferencia que Strawson menciona entre la metafísica descriptiva y el análisis conceptual, la primera se inscribe básicamente en la tradición de la segunda en el sentido de que la metafísica descriptiva es una manera de llevar a cabo el análisis conceptual y esto por dos motivos. Un motivo radica en que Strawson habla de su método en términos de una concepción particular del "análisis filosófico". ${ }^{6} \mathrm{El}$ otro motivo radica en que Strawson (1967, p. 324) se inscribe en la tradición analítica en el sentido de que "la tarea principal del filosófo es la comprensión de cómo funciona nuestro pensamiento acerca de las cosas, y [...] no podemos averiguar ese funcionamiento excepto fijándonos cómo usamos las palabras". 7 Lo que interesa es analizar la estructura del pensamiento y esto no consiste en un estudio de los procesos psicológicos, sino en un estudio del lenguaje. A su vez, este estudio no consiste en dar cuenta del

\footnotetext{
${ }^{5}$ Aquí, la oposición se da, en el terreno conceptual, con aquellas teorías que buscan reducir un concepto a sus elementos simples (por ejemplo, el atomismo de Russell). Sin embargo, se verá más adelante por qué la oposición con Quine en el terreno ontológico refleja esta polémica en el terreno conceptual.

${ }^{6}$ Cfr. Strawson 1997a, caps. 1 y 2.

${ }^{7}$ Esto concuerda con la definición de Dummett (1990) de la filosofía analítica.
} 
uso efectivo de ciertos términos en un lenguaje particular, tal como lo hacían los filósofos del lenguaje ordinario de la escuela de Oxford, sino en la descripción de las conexiones entre los términos de nuestro lenguaje. ${ }^{8}$ Así, lo que a Strawson le interesa son los rasgos fundamentales que aparecen en todo lenguaje, y para exhibir esos rasgos es necesario un análisis profundo, puesto que en general no aparecen en la superficie del lenguaje. Si a esto le sumamos que el análisis del lenguaje no sólo es un medio para dar cuenta de la estructura del pensamiento, sino que a su vez esta estructura del pensamiento es paralela, en algún sentido, a la estructura básica de la realidad (ontología) y del conocimiento (epistemología), lo que se obtiene es la particular interpretación de Strawson de la filosofía analítica. ${ }^{9}$

El segundo sentido de la formulación del método es el de la concepción gramatical del análisis filosófico. Según Strawson, uno puede entender el análisis conceptual acudiendo a dos analogías. Una es la analogía con una terapéutica, la otra con una gramática. En el primer caso, lo que se ofrece es una técnica para curar ciertos desórdenes intelectuales producto, en especial, de confusiones conceptuales y falsos modelos; la terapéutica consiste en mostrar el uso correcto de los conceptos. Puesto que la concepción terapéutica es la wittgensteniana, dejaré para el apartado siguiente su desarrollo y me concentraré en la filosofía como gramática.

Strawson ofrece tres analogías. En primer lugar, así como tenemos un conocimiento implícito de la gramática de una lengua, tenemos un conocimiento implícito de los conceptos de nuestro esquema conceptual. En ambos casos, uno no aprende a utilizar los términos/conceptos al aprender una teoría explícita sobre su uso, sino de manera práctica. En segundo lugar, así como (y habría que agregar: en condiciones normales) no se pierde el dominio de la gramática de la lengua nativa, tampoco se pierde el dominio de nuestro bagaje conceptual. Sabemos cómo usarlo tanto al hablar como al pensar sin que por ello tengamos que saber formular las reglas que lo gobiernan, por ende, y ésta es la tercera cuestión, así como la utilización de una gramática no implica conocer explícitamente los principios que la gobiernan, emplear los conceptos tampoco requiere que sepamos explícitamente las reglas que permiten relacionarlos.

De esta manera, la tarea de un gramático y la de un filósofo son análogas en la medida en que así como el gramático busca una explicación sistemática del sistema de reglas gramaticales, el filósofo busca una explicación sistemática de la estructura conceptual. Tanto de la gramática como

${ }^{8}$ Sigo a Dummett (1990, p. 537) en su consideración de que el estudio de Austin era empírico.

${ }^{9}$ Volveré más adelante sobre este paralelismo entre los planos conceptual/lingüístico y ontológico. A lo largo de este trabajo no me ocuparé del plano epistemológico, no porque no sea pertinente, sino porque considero que la polémica con Wittgenstein y Quine se centra, en particular, en los otros planos. Con 'paralelismo' quiero dar a entender que hay distinciones fundamentales en un plano que tienen su correlato (o fundamentación) en los otros planos. 
de la estructura conceptual tenemos un dominio tácito e inconsciente, la tarea del filósofo gramático consiste en explicitar lo que sabemos implícitamente, es decir, en poner de manifiesto los principios que están implícitos en el uso de los conceptos. Puesto que de lo que se trata es de explicitar una práctica, el objetivo del filósofo gramático no se alcanza a través de alguna técnica práctica, sino por medio de la exhibición de las relaciones entre los conceptos, esto es por análisis filosófico. Lo que se busca es la "gramática de nuestro pensamiento ordinario" o, lo que es lo mismo, la "teoría de nuestra práctica conceptual" (Strawson 1997a, p. 53). De manera que la gramática conceptual busca ser sistemática en el sentido de ofrecer una teoría acerca de una práctica (en contraposición a lo que sería el análisis de numerosos casos inconexos entre sí), y se intenta ofrecer una teoría porque se asume que hay una estructura implícita de relaciones entre los conceptos de nuestro esquema conceptual. En mi opinión, la analogía es más fuerte de lo que se piensa, ya que supone el paralelismo entre la estructura de nuestro esquema conceptual y la estructura de una teoría acerca de nuestro esquema conceptual. La idea subyacente sería que dado que nuestro esquema conceptual está estructurado (de alguna manera que hay que explicitar) como un sistema, el resultado de esta explicitación no puede ser más que un conjunto de elementos relacionados de cierta manera, es decir, un sistema.

Hasta aquí, la tarea de la filosofía consiste en describir los rasgos fundamentales de nuestro esquema conceptual (metafísica descriptiva) de manera que sea posible ofrecer una teoría acerca de nuestra práctica conceptual (concepción gramatical). Veremos a continuación qué especificación incorpora el tercer sentido del método de la filosofía. Entre las concepciones del análisis filosófico que son sistemáticas o positivas, Strawson propone su modelo de la conexión o análisis conectivo en oposición al modelo o análisis reductivo/constructivo. Este último consiste en descomponer un concepto o una idea compleja en sus elementos mostrando sus relaciones hasta llegar a las ideas simples que son el límite ideal del análisis. Una vez realizado esto, el objetivo es mostrar cómo las ideas complejas pueden reconstruirse lógica o conceptualmente a partir de las ideas simples. ${ }^{10}$ Este modelo reductivo tiene varios problemas además de que históricamente no tuvo éxito. Strawson no hace hincapié en esto último, sino sólo en el problema de la circularidad, a saber, que parece muy difícil que en el proceso de descomposición de un concepto complejo no se inmiscuya el mismo concepto que se quería analizar.

En contraposición, y para evitar el peligro de la circularidad perniciosa, el análisis conectivo no requiere llegar a elementos simples. El modelo consiste en "una elaborada red, de un sistema, de elementos conectados entre

${ }^{10}$ Ejemplos de esto son las impresiones simples de Hume y el atomismo lógico de Russell. 
sí, de conceptos; un modelo en el que la función de cada elemento, de cada concepto, sólo puede comprenderse apropiadamente desde el punto de vista filosófico captando sus relaciones con los demás, su lugar en el sistema" (Strawson, 1997a, p. 63). En este holismo semántico, la circularidad se torna virtud, porque con el fin de esclarecer un concepto, no importa si en su análisis se vuelve a pasar por el punto de partida, Strawson (1997a, p. 64) cree que es un "círculo amplio, revelador e iluminador".

Ahora bien, el hecho de que no se requieran elementos simples no implica que no haya conceptos más fundamentales que otros, esto es, conceptos cuya falta provocaría que no se pudiese tener otros. Es justamente esta idea la que pareció atraer a los seguidores del análisis reductivo. Así, la habilidad de utilizar los conceptos de las ciencias presupone la posesión de conceptos preteóricos de la vida cotidiana, pero no a la inversa, esto quiere decir que los últimos son conceptualmente anteriores y en ese sentido Strawson los denomina conceptos básicos. Ejemplos de conceptos básicos son: tiempo, cambio, verdad, conocimiento, identidad. ${ }^{11}$

Los conceptos básicos poseen tres características: son generales en el sentido de ser omnipresentes, son irreducibles dado el holismo semántico y son no contingentes en dos sentidos distintos, uno débil y otro fuerte. ${ }^{12}$ Antes de explicitar estos sentidos quisiera aclarar que los conceptos básicos son contingentes en el sentido de que podríamos haber tenido otros completamente diferentes si nuestra forma de vida hubiera sido diferente, es un accidente natural y social que sean los que son. Pero, una vez que son los que son, cabe la posibilidad de considerarlos necesarios, así, el sentido fuerte afirma que los conceptos básicos son elementos necesarios de nuestra estructura conceptual sin los cuales la experiencia nos resultaría ininteligible. El sentido débil no los afirma con necesidad. ${ }^{13}$

Ahora estamos en condiciones de completar la metodología strawsoniana para la filosofía en virtud de la sugerencia hecha más arriba de que cada manera de formularla introduce una especificación. La tarea de la filosofía consiste en describir los rasgos fundamentales de nuestro esquema conceptual (metafísica descriptiva) de manera de ofrecer una teoría acerca de nuestra práctica conceptual (concepción gramatical), teoría que consiste en mostrar las conexiones entre los rasgos inmutables de nuestro esquema conceptual, es decir, entre los conceptos básicos (análisis conectivo).

Ahora bien, he dicho antes que el alma de la filosofía de Strawson consiste en la dualidad entre la referencia y la predicación, y su fundamentación ontológico-epistemológica, y que el análisis conectivo está pensado para

\footnotetext{
11 Véase Strawson 1997a, p. 68.

${ }^{12}$ Cfr. Strawson 1997a, p. 69.

${ }^{13}$ Strawson da cabida aquí a posibles objeciones. Con respecto al sentido fuerte se puede objetar que no hay ningún tipo de argumento que pueda mostrar que un concepto es necesario. En caso de que se concuerde con esta objeción, queda el sentido débil.
} 
establecer las conexiones entre las dualidades (y los conceptos asociados a ellas) de los distintos ámbitos. Algunos sostienen que es el uso de argumentos trascendentales lo que le permite a Strawson establecer las relaciones entre los elementos de nuestro esquema conceptual y que, en este sentido, su uso es constitutivo del análisis conectivo. Así, el uso de argumentos trascendentales constituiría una tercera tesis metafilosófica (o metodológica): (iii) el uso de argumentos trascendentales es indisociable del análisis conectivo. Más adelante pondré en duda esta tesis, aunque concuerdo en que los argumentos trascendentales cumplen cierto papel a la hora de establecer las conexiones entre los rasgos de nuestro esquema conceptual. ${ }^{14}$

\footnotetext{
${ }^{14}$ Algunos consideran que Strawson adopta como interlocutor al escéptico, y por ende que estos argumentos trascendentales están concebidos como argumentos antiescépticos, y que esta asociación es un aspecto fundamental de la metodología strawsoniana porque es lo que le permite ampliar el alcance del análisis conceptual tradicional a fin de determinar los rasgos fundamentales de nuestro esquema conceptual. No concuerdo con la idea de que esta asociación constituye un rasgo fundamental de la metodología strawsoniana. En primer lugar, el interlocutor principal de Strawson en relación con lo que antes se denominó el alma de su filosofía no es el escéptico, sino posturas que no reconocen la dualidad fundamental, una de cuyas expresiones es la de sujeto-predicado. Ejemplos de estas posturas serían la propuesta de regimentación lógica del lenguaje de Quine, la semántica formal de Tarski, el construccionismo lingüístico de Carnap, la gramática transformacional de Chomsky (Cfr. Tse 1998). En este sentido, Individuals, libro en el que se concentrarían algunos de los argumentos trascendentales más importantes (los otros son 1966 y 1985), más que una discusión contra el escéptico que cuestiona la existencia de objetos materiales es un desarrollo de su preocupación por los objetos fundamentales de referencia (Cfr. Strawson 1998a). Esto no quiere decir que el escepticismo no sea una preocupación para Strawson, sino tan sólo que no es su interlocutor principal. Por otro lado, si bien se podría interpretar que Skepticism and Naturalism (1985), tiene como interlocutor principal al escéptico, creo que, pace el título del libro, comprenderlo de esa manera conduce a un equívoco. Strawson discute allí con el naturalista reduccionista sobre las propiedades morales, fenoménicas, mentales y las entidades abstractas. Como Strawson mismo reconoce, llamar escépticos a estos tipos de reduccionismos no es la palabra justa, es mejor el adjetivo 'reduccionistas' y por eso invita a no poner énfasis en la noción de escepticismo (p. 68). En segundo lugar, Strawson no concibe los argumentos trascendentales como argumentos antiescépticos. Strawson (1985, cap. 1) sostiene que esta conexión que establece Stroud (1968) es cuestionable. Por un lado, porque es inútil combatir al escéptico con argumentos, puesto que de lo que se trata es de las presuposiciones que forman parte de nuestro marco conceptual. Dado que el escéptico plantea su duda en términos de este mismo esquema, a la vez que repudia las condiciones necesarias de su existencia, su planteamiento es irresoluble en estos términos. Por ello, cuando se ocupa, por ejemplo, de la dualidad desde el punto de vista epistemológico, afirma que no está planteando ni resolviendo un problema escéptico, sino conectando las partes de nuestra estructura conceptual (Cfr. Strawson 1997a, cap. 5). A Strawson no le preocupa si los argumentos trascendentales no refutan al escéptico, porque lo que interesa es el papel que tienen en la investigación de las conexiones entre los conceptos de nuestro esquema conceptual. Por otro lado, en cuanto argumentos trascendentales, Strawson no se pronuncia sobre la validez de los mismos, aunque cree que algunos son válidos; por ejemplo, el que utiliza para mostrar la existencia de otras mentes ( $C f r$. Strawson 1997a, cap. 1). Así, cuando se ocupa de esto último, sostiene que la aceptación de ciertos presupuestos que conforman nuestro esquema conceptual (ciertas condiciones necesarias de su existencia) no tiene como objetivo evitar el escepticismo, sino la explicación de la existencia de nuestro esquema conceptual (Cfr. Strawson 1959, cap. 3).
} 


\section{El análisis conectivo y la concepción terapéutica de la filosofía}

Para Wittgenstein, los términos tienen un uso en el lenguaje natural y hay que describirlo para evitar caer en confusiones que llevan a pseudoproblemas filosóficos. La cuestión radica en describir, de manera adecuada, la gramática de las palabras, pues hay modos de hablar que confunden. Por ejemplo, en el caso del vocabulario psicológico, cuando no es posible encontrar algún objeto material que una palabra denota, se tiende a (cometer el error de) creer que denota un "objeto etéreo". El origen de la confusión reside en que asimilamos estos términos a los que denotan y así nos vemos llevados, por el uso aparentemente similar de dichas palabras, a buscar algún tipo de actividad o estado que corresponda a su expresión lingüística (CAM, p. 34). Éste es sólo un ejemplo del origen de la confusión conceptual; pero, en general, las confusiones ocurren en parte también porque somos presos de ciertas ilusiones o modelos erróneos acerca del lenguaje, y en particular, del significado de las expresiones. La función de la filosofía es entonces curar las confusiones conceptuales, el filósofo es el terapeuta que cura la enfermedad de la confusión (PI, § 255).

Así, la cura radica en describir de manera adecuada la gramática de las palabras. Esto se puede hacer por medio del análisis. Por ejemplo, cuando establecemos una analogía entre expresiones con distintos usos que nos lleva a confusiones podemos eliminar una expresión "sustituyendo una forma de la expresión por otra; esto puede llamarse un 'análisis' de nuestras formas de expresión, pues el proceso tiene a veces semejanza con una descomposición" (PI, § 90). Pero este proceso de descomposición no consiste en llegar a los elementos simples, porque eso es una ilusión, no hay algo así como un "análisis último de nuestras formas de lenguaje, y así una única forma completamente descompuesta de la expresión. Es decir: como si nuestras formas de expresión usuales estuviesen, esencialmente, aún inanalizadas; como si hubiera algo oculto en ellas que debiera sacarse a la luz" (PI, § 91). Las confusiones se descomponen cuando describimos la gramática de una palabra, y hacer esto consiste en mostrar los contextos en que las expresiones son usadas correctamente (e incorrectamente), de manera de exhibir las conexiones adecuadas (e inadecuadas) entre los conceptos. Mostrar la gramática de un concepto no lleva a ningún descubrimiento, a ningún conocimiento nuevo, puesto que es algo que todo usuario del lenguaje ya conoce. Al filósofo le interesa mostrar las conexiones entre los conceptos con el objetivo de disolver problemas filosóficos (PI, § 132 y ss.). De ahí el carácter terapéutico del análisis. Un problema filosófico implica que hay una confusión, disolverla es disolver el problema, y todo lo que se requiere para disolver confusiones conceptuales está a nuestro alcance, en nuestro conocimiento cotidiano de cómo usar las expresiones. 
Se puede ver en Wittgenstein una conexión entre su concepción gramatical del análisis y su concepción semántica. Para Wittgenstein, los términos no poseen un significado fijo, determinado, puesto que los fenómenos no poseen algo en común que nos permita incluirlos bajo una misma palabra. No hay un conjunto de rasgos necesarios y suficientes para que llamemos a algo 'comprensión' o 'pensamiento' o 'silla' (GF, p. 229) o con cualquier otro término. Los términos indican una compleja red de rasgos similares que se entrecruzan dando lugar a "parecidos de familia" (PI § 67). Las distintas maneras de usar las palabras dependen de los distintos "juegos del lenguaje" (PI, $\S \S 65,66)$. Así, comprender una palabra o una frase requiere comprender un lenguaje, es decir, dominar una técnica para usarla, técnica que dominamos al aprender un lenguaje (GF, p. 75) y que es compartida puesto que compartimos una "forma de vida" (PI, § 241). Ésta es lo dado (PI, p. 517). De manera que nuestro lenguaje está relacionado con el mundo porque forma parte de éste; es parte tanto de nuestra historia natural como de nuestras prácticas sociales (PI, § 25).

Para conocer o atribuir significados no hace falta salir del entramado del lenguaje; lo que permite conectar las palabras con el mundo no es algo que esté en la mente, tampoco ninguna clase de esencia real de los fenómenos. Lo único que se requiere son criterios que nos permitan dar el significado de las oraciones que emitimos. Estos criterios consisten en otras oraciones que justifican el significado de las oraciones que emitimos. Los criterios de la comprensión en general se adquieren cuando aprendemos un lenguaje y consisten en el uso correcto de las palabras o en poder dar una explicación del significado (GF, p. 42). Saber cómo aplicar un término o ser capaz de responder a preguntas relacionadas con el término en cuestión —por ejemplo, “¿qué significa tal término?"- permite precisar su significado. De lo expuesto se puede ver, tal como mencioné antes, que la concepción gramatical del análisis requiere cierta concepción semántica. Parece que la descripción de la gramática de los conceptos supone, en algún sentido, algún tipo de concepción acerca de cómo se adquieren las palabras, en qué consiste dominar un término, en dónde radica su significado, cuáles son sus criterios de corrección, etcétera.

Hay dos cuestiones que quisiera subrayar con respecto a las relaciones entre las concepciones de Strawson y Wittgenstein. En primer lugar, lo que les interesa a ambos es describir nuestra práctica lingüística ordinaria. En este sentido, comparten la tesis metafilosófica (ii'), e incluso comparten la idea de que no se trata de un estudio empírico acerca de cómo los hablantes utilizan sus conceptos, al estilo de la filosofia del lenguaje ordinario de Austin, ${ }^{15}$ sino de mostrar las conexiones conceptuales entre los términos. En este sentido, ni Wittgenstein ni Strawson hacen análisis filosófico en el

${ }^{15}$ Véase la nota 8. 
sentido tradicional del análisis reductivo-constructivo, sino en el sentido de "elucidación" (clarificación). El análisis no consiste en la descomposición de términos complejos en constituyentes simples (Russell) ni en la tarea constructiva de reconstruir lógicamente los conceptos complejos a partir de sus constituyentes (Carnap). Y esto por cuestiones metodológicas (Strawson) o semánticas (Wittgenstein). Para Strawson, el modelo conectivo es más realista y fructífero en el sentido de ser más comprehensivo que el reduccionista. ${ }^{16}$ Para Wittgenstein no hay algo así como una forma final y única que adopta el análisis de las expresiones linguísticas (PI, § 91) y esto es así por su concepción del significado.

El sentido de análisis conectivo o elucidatorio en el que tanto Wittgenstein como Strawson se inscriben consiste en: "dar una descripción, para propósitos específicamente filosóficos, del uso de una expresión lingüística y de sus conexiones gobernadas por reglas con otras expresiones por medio de implicación, exclusión, presuposición, etc.” (Hacker 1996, p. 8). Se puede ver claramente que el análisis de Strawson se acomoda perfectamente a esta definición. Con Wittgenstein sucede lo mismo, sólo que habría que hacer algunas aclaraciones. Tal como Strawson presenta su análisis conectivo, como contrapuesto al terapéutico, parece que no habría posibilidad de encontrar nada en común más allá de lo que él considera que ambos comparten; esto es, que se ocupan del uso real de los conceptos en los ámbitos que les corresponden. Pero lo cierto es que no hay nada que los haga incompatibles, y de hecho en Wittgenstein mismo se puede encontrar una combinación de ambos.

Se puede aceptar que el análisis terapéutico posee, tal como Strawson lo afirma, un "espíritu negativo", a diferencia del "espíritu positivo" del análisis conectivo, puesto que de lo que se trata es de eliminar la confusión conceptual sin poner nada en su lugar (PI, § 124). Sin embargo, suponiendo que se esté muy interesado en "no poner nada en su lugar", aun así cuando queda realizado el análisis terapéutico, el residuo exhibe ciertas relaciones adecuadas entre conceptos. Se resuelven las confusiones describiendo cómo usamos el lenguaje, haciendo explícitas ciertas reglas familiares que gobiernan el uso de las expresiones. En este sentido, se exhiben las intrincadas conexiones entre los conceptos para obtener una visión adecuada del campo en el que se produjo la confusión inicial, y esto último es lo que queda tanto si se hace análisis terapéutico como si se efectúa el conectivo. En palabras de Wittgenstein: "Una fuente principal de nuestra falta de comprensión es que no vemos sinópticamente el uso de nuestras palabras. - A nuestra gramática le falta visión sinóptica. La representación sinóptica produce la comprensión que consiste en "ver conexiones'" (PI, $\S 122$ ). Se puede hacer más o menos hincapié en el aspecto negativo, y

${ }^{16}$ Cfr. Strawson 1997, p. 63. 
apegarse a la terapéutica (como lo hizo Wittgenstein la mayoría de las veces), o se puede enfatizar el aspecto positivo. En todo caso, creo que es una cuestión de actitud; lo que queda exhibido, finalmente, son las relaciones entre los conceptos. Ambos establecen conexiones entre conceptos, sólo que los objetivos o las intenciones son distintos. ${ }^{17}$

En segundo lugar, aun si se concuerda con lo dicho en relación con el criterio "espíritu positivo o negativo", esto es, que es una cuestión tan sólo de actitud y que no apunta al resultado del análisis, no obstante, se puede insistir, tal como Strawson lo hace, en el criterio "sistemático-asistemático". Strawson enfatiza que su postura es constructiva o sistemática en el sentido de que el objetivo del análisis es construir una teoría acerca de nuestra práctica conceptual ordinaria. Ahora bien, hay varios sentidos en el que un análisis puede ser sistemático. Dummett (1990), al hablar de si la filosofía analítica puede ser sistemática, ofrece dos: 1) una teoría es sistemática a la manera de las teorías articuladas de los grandes sistemas filosóficos, y 2) una investigación es sistemática si procede de acuerdo con ciertos métodos generalmente aceptados y según criterios también generalmente aceptados para rechazar o aceptar sus resultados.

Con respecto a 1), está claro que no es el objetivo ni de Strawson ni de Wittgenstein elaborar un sistema filosófico; eso sería hacer metafísica revisionista y hemos visto que ambos análisis se inscriben en el ámbito descriptivo. De lo que se trata es de describir nuestras prácticas lingüísticas/conceptuales. Ni en el análisis conectivo ni en el terapéutico/conectivo se intenta producir "una estructura mejor" para interpretar la realidad. En cuanto a 2), éste es un sentido bastante fuerte de sistematicidad en el cual no sólo no encajarían los análisis de Strawson y de Wittgenstein, sino, problamente, lo que sea que haya producido toda la historia de la filosofía. Además, no es el sentido de sistematicidad que le interesa a Strawson; su objetivo es lograr una comprensión articulada de nuestra habilidad para usar conceptos, una teoría acerca de nuestra práctica conceptual, y para esto el análisis conceptual es el método que considera apropiado, pero no porque crea que es (o debe ser) el método aceptado por la comunidad filosófica. ${ }^{18}$

Por otro lado, en cuanto a los resultados, si uno piensa en las teorías como si proveyeran un conocimiento nuevo, creo que esto no se aplica a Strawson. Ya hemos visto que el análisis no promete ninguna visión reveladora ni ninguna estructura mejor. Hay un sentido, a mi entender, en el que ni el análisis de Wittgenstein ni el de Strawson producen conocimiento nuevo. El análisis terapéutico se encarga de disolver confusiones;

17 Cfr. Hacker 1996, p. 176, en apoyo de esta conclusión.

${ }^{18}$ Se podría pensar que 2) se acerca a la idea de un sistema deductivo. Strawson (1985, p. 23) rechaza esto explícitamente. Por otro lado, pensar que existe "el" método de la filosofía iría en contra de su espíritu "tolerante". 
el resultado, si se coincide conmigo, es una representación de las relaciones conceptuales adecuadas en un ámbito particular de nuestro lenguaje. El análisis conectivo explicita lo implícito; es decir, pone de manifiesto lo que está implícito en nuestras prácticas, pero explicitar conlleva la idea de algo que ya estaba y, en ese sentido, no es nada nuevo. En ambos tipos de análisis lo que tenemos es un conjunto de descripciones, quizá un reordenamiento de ciertas relaciones que ya estaban ahí, un esclarecimiento de las mismas (ya sea porque estábamos confundidos (Wittgenstein) y las opacamos, o porque no estaban explícitas (Strawson)).

Ahora bien, la cuestión de la sistematicidad se traslada entonces a aquello que se reordenó, porque un reordenamiento puede ser sistemático o no. Así, se podría pensar que si bien Wittgenstein en general no hacía un tratamiento sistemático de una cuestión, de todas formas se podría reorganizar la gramática de ciertos conceptos (por ejemplo, los psicológicos como pensar, imaginar, comprender, etc.) de manera de tener una "visión sinóptica o clara" de las relaciones entre estos conceptos. Así se podría elaborar una postura sistemática de los temas de los cuales se ocupó Wittgenstein. ${ }^{19} \mathrm{De}$ hecho es lo que los exégetas de este filósofo suelen hacer y, ese sentido, si sistemático significa: 3) discutir en detalle ciertos temas de manera de interrelacionarlos en una red, entonces Wittgenstein fue sistemático (aunque su propio método de exposición haya sido aforístico).$^{20}$ Esto nos remite al análisis conectivo, si sistemático es igual a análisis conectivo, y vimos que el análisis de Wittgenstein se puede interpretar como conectivo, entonces no quedaría nada por discutir.

Sin embargo, parece que la noción de teoría sistemática que utiliza Strawson se basa en 4) la idea de obtener ciertos principios generales (que rigen la práctica conceptual) ${ }^{21}$ y 5) la idea de una estructura o sistema subyacente general. ${ }^{22}$ Con respecto a 4 ), el énfasis está puesto en la idea de "principios generales". Strawson sostiene que el resultado del análisis no sólo es la explicitación de ciertas relaciones entre los conceptos, sino que esa explicitación tiene la forma de principios; así, la comprensión de nuestra práctica conlleva un conjunto de principios que la rigen (en oposición a descripciones inconexas de los usos)..$^{23}$ Ese conjunto de principios vale para toda la práctica conceptual, por eso el énfasis puesto en la "generalidad". Los principios están articulados en una estructura o sistema subyacente a nuestra práctica conceptual. Es así como los sentidos 4) y 5) están estrechamente relacionados.

\footnotetext{
${ }^{19}$ En Hacker 1996, p. 30, nota 13, se sugiere lo mismo.

${ }^{20}$ Cfr. Hacker 1996, p. 192.

${ }^{21}$ Cfr. Strawson 1997a, p. 53.

${ }^{22}$ Cfr. Strawson 1997a, p. 52.

${ }^{23}$ Cfr. Strawson 1997a, p. 53.
} 
Ahora bien, este sentido de sistematicidad le debe mucho, en mi opinión, al paralelismo sostenido por Strawson entre los ámbitos conceptual/lingüístico-ontológico. Dado que nuestro esquema conceptual consiste en una estructura coherente de interconexiones entre conceptos, cualquier descripción de esa estructura debe reflejar esa misma forma. Decir que no se puede tener una teoría sería como decir que no hay relaciones generales entre los conceptos de nuestro esquema conceptual (lo cual sería como decir que no hay relaciones generales entre los términos de nuestro lenguaje, lo cual sería como decir que no hay relaciones generales entre las entidades de nuestra ontología). No se me ocurre de qué manera se puede entender la insistencia de Strawson en que cualquier análisis que dé como resultado una descripción de las relaciones conceptuales sin este aspecto de generalidad no llega a cumplir "la demanda metafísica de comprensión" (Strawson 1959, p. 10) si no es en función de este paralelismo.

Está claro, para cualquier lector de Wittgenstein, que la descripción de la gramática de los conceptos no es general en el sentido de que se obtengan ciertos principios que conformen una teoría lingüística. Esto es así porque la filosofía no tiene como objetivo lograr un conjunto de verdades, una teoría; ésa es la tarea de la ciencia. ${ }^{24}$ Es conocida la distinción wittgensteiniana entre ciencia y filosofía que se establece en función de ciertas distinciones entre conceptos que pertenecen a estos ámbitos, como, respectivamente, explicación-descripción, causa-razón, empírico-conceptual. En general, se considera que Wittgenstein no elaboró una teoría del lenguaje sistemática, y el argumento que se utiliza es que Wittgenstein mismo rechazaba la sistematicidad por motivos que radican en la distinción ciencia-filosofía.

Sin embargo, esta tesis metafilosófica acerca de la relación entre la filosofía y la ciencia, que podría resumirse en $\left(\mathrm{i}^{\prime \prime}\right)$ : la filosofía y la ciencia constituyen dos ámbitos independientes, puede rechazarse con la consecuente posibilidad de una sistematización de las clarificaciones conceptuales llevadas a cabo por Wittgenstein. ${ }^{25}$ Sólo una tesis sustantiva filosófica (y no metafilosófica) constituiría una razón de peso para que dicha sistematización no fuera posible. Más adelante se considerará una razón filosófica de peso, pero ahora se explicitará en qué sentido sería posible esta sistematización. Cuando Strawson habla de la "teoría de una práctica" parece que no está hablando de una teoría del lenguaje, al menos no parece ser el objetivo de Strawson ni lo que de hecho elaboró. Lo que Strawson dice es que tiene que haber principios generales acerca de la práctica conceptual. Esos principios se extraen de un análisis de ciertas funciones de nuestro

\footnotetext{
${ }^{24}$ Véase Hacker 1996, p. 110.

${ }^{25}$ Puede rechazarse porque es independiente del análisis terapéutico/conectivo propiamente dicho. En este sentido se puede asociar este análisis con tesis metafilosóficas que apunten a la sistematicidad.
} 
discurso como la referencia, la identificación, la reidentificación y la predicación. A partir del análisis de estas funciones estableció ciertos rasgos fundamentales de nuestro discurso: su articulación en sujeto y predicado, que refleja la distinción ontológica entre particulares y universales, y la distinción epistemológica entre objetos perceptuales y conceptos. Ahora bien, ¿qué diferencia en grados de generalidad habría entre el principio general de que nuestro discurso está articulado en sujeto y predicado y la afirmación de que el significado no consiste en nada que el individuo tenga en la cabeza o algo del mundo, sino que consiste en el uso? ¿Acaso la última tiene un alcance menor que la primera? Quizá sea cierto que las reconstrucciones de la concepción semántica de Wittgenstein no llevan a una teoría completamente delineada, pero no es cierto que no haya principios generales (tal como exige 4)) que no valgan para cualquier tipo de actividad lingüística; de hecho, la noción de significado (como uso) parece valer para cualquier descripción de los juegos del lenguaje.

No obstante, parece que se puede objetar a esto que en la misma concepción filosófica de los juegos del lenguaje radica la imposibilidad de una sistematización; así, no sabríamos cómo extender las descripciones de los juegos del lenguaje a la totalidad del lenguaje dado que no parece haber ninguna estructura conceptual/lingüística compartida por todos los juegos del lenguaje. ${ }^{26}$ Dicho de otro modo, si hubiera una estructura conceptual, seguramente los juegos del lenguaje reflejarían las relaciones sistemáticas entre los rasgos de esa estructura. Ciertamente, no parece haber nada en las descripciones de los diferentes fragmentos de nuestra práctica lingüística que permita conectarlos entre sí.

Sin embargo, los juegos del lenguaje requieren aprender un lenguaje, y este aprendizaje no consiste en la adquisición de fragmentos aislados, sino en la adquisición de una técnica que es compartida por todos los individuos, puesto que compartimos una "forma de vida". Si bien el compartir comportamientos y prácticas sociales constituye un rasgo no lingüístico y por ende no serviría para establecer elementos compartidos de nuestro sistema conceptual, hay ciertos supuestos básicos que "dentro del sistema total de nuestros juegos del lenguaje forma[n] parte de los fundamentos" (SC, $\S 411$, las cursivas son mías), constituyen "el andamiaje de todas nuestras consideraciones" (SC, § 211), "pertenece[n] a nuestro sistema de referencia" (SC, § 83). Wittgenstein utiliza distintas expresiones, como 'andamiaje', 'sistema de referencia', 'trasfondo' (SC, § 94), 'sustrato' (SC, § 162) para expresar la idea de que hay ciertos elementos (proposiciones) de nuestro

${ }^{26}$ Esta objeción se inspira en observaciones de Dummett de que no sabríamos cómo desarrollar una "filosofía general del lenguaje coherente" (1990, p. 548), y que los juegos del lenguaje "no parecen un modelo prometedor para una descripción sistemática de todo el lenguaje" (1990, p. 549). 
sistema de creencias que forman parte de nuestro marco de referencia, y en este sentido no pueden ser puestos en duda. ${ }^{27}$

No me voy a extender en este punto porque mi intención es tan sólo mostrar que no habría, en principio, ningún obstáculo en la concepción de los juegos del lenguaje que impida la posibilidad de afirmar que hay un esquema conceptual que subyace al sistema total de los juegos del lenguaje, tal como exige 5). En este sentido, no habría impedimentos para establecer conexiones entre los elementos de este sistema subyacente general. Strawson (1985, cap. 1) mismo rescata este aspecto en Wittgenstein como antecedente de su tarea de investigación de aquellos rasgos básicos de nuestro esquema conceptual que constituyen nuestra "visión del mundo" (expresión tomada de Wittgenstein (SC §162)) y que muestran nuestros "compromisos ineludibles que no elegimos y a los cuales no podemos renunciar" (Strawson 1985, p. 28). ${ }^{28}$

En resumen, se puede sostener que hay razones para pensar que el análisis terapéutico/conectivo no es un obstáculo para el desarrollo de un sistema en los sentidos pertinentes 3)-5). Si bien Wittgenstein se opone a la filosofía como sistema, pace su tesis metafilósofica, por medio del análisis terapéutico/conectivo es posible 3) interrelacionar conceptos en una red (en eso consisten las descripciones de los juegos del lenguaje), 4) obtener principios generales (a partir de la reconstrucción, tal como lo han hecho muchos filósofos, de su teoría acerca del significado, la cual está presupuesta, como lo mencioné antes, en la descripción de la gramática de los conceptos en 3)), y 5) investigar el sistema subyacente general (de hecho es a través del análisis terapéutico/conectivo de 'conocer' como Wittgenstein llega a postular la existencia de ciertas proposiciones básicas de nuestro sistema conceptual).

Lo que intenté mostrar en este apartado es que los dos peligros del análisis terapéutico que Strawson menciona, el espíritu negativo y la asistematicidad, no constituyen una amenaza para el análisis conectivo. Con respecto al primero, hemos visto que ambos métodos se inscriben en la tradición de la descripción del lenguaje ordinario (esto es, comparten la tesis metafilosófica (ii') y que la diferencia entre los análisis en cuestión

${ }^{27}$ Si bien en la metáfora del río (SC, §§ 96-99), no hay una relación fija entre los elementos solidificados y los que fluyen, en $\S 99$ parece establecerse una relación no tan intercambiable entre estos elementos.

${ }^{28}$ La cuestión de si en la concepción de los juegos del lenguaje habría algún marco compartido es un asunto polémico y que requeriría un análisis profundo que no es posible realizar aquí. Sin embargo, si bien el mismo Wittgenstein favoreció una concepción fragmentada del lenguaje (y esto por motivaciones metafilosóficas en contra de la sistematicidad), lo único que me interesa subrayar es que, pace él mismo (y de que no se haya ocupado de profundizar en este punto debido a la falta de motivaciones metafísicas), habría algunos indicios en dirección a que ciertas conexiones entre conceptos (creencias o proposiciones) formarían parte del andamiaje que constituye nuestra "visión del mundo". 
es de actitud y que ésta no afecta el resultado final del análisis, esto es una "visión sinóptica o clara" de nuestros conceptos. Con respecto al segundo, hemos visto que la diferencia radica más bien en un aspecto, de la tesis metafilosófica ( $\left.i^{\prime \prime}\right)$ que relaciona filosofía con asistematicidad que puede independizarse del análisis, y no parece haber un argumento sustantivo filosófico que torne incompatible la utilización del análisis terapéutico/conectivo de manera sistemática. Veremos a continuación si la tesis (iii) lleva a que el análisis terapéutico/conectivo constituya una amenaza para la tarea del análisis conectivo.

Si se entiende que los argumentos trascendentales son una condición (o rasgo) necesaria y suficiente del análisis conectivo, entonces, Strawson no sostiene (iii). No son una condición suficiente porque la sola utilización de argumentos trascendentales no constituye de por sí la realización de un análisis conectivo. En la historia de la filosofía habría muchos ejemplos obvios de utilización de argumentos trascendentales que no están asociados a la metodología conectiva tal como se la especificó antes. Tampoco son una condición necesaria porque Strawson hace uso de argumentos que no son trascendentales y que permiten igualmente establecer el alcance de nuestro esquema conceptual, sobre todo cuando trata la dualidad y la asimetría entre sujeto y predicado. ${ }^{29}$ Esto muestra que el papel de establecer las conexiones conceptuales no es privativo de los argumentos trascendentales. Así, el análisis conectivo no está indisolublemente asociado a ningún tipo particular de argumentos. ${ }^{30}$ Es por ello que cuando Strawson expone en qué consiste su método, no menciona, hasta donde sé, que la utilización de los argumentos trascendentales sea constitutiva del análisis conectivo. ${ }^{31}$ Cuando da las razones por las cuales considera que el análisis terapéutico (y el reduccionismo ontológico quineano) constituye(n) una amenaza para el establecimiento de estas conexiones, tampoco menciona, hasta donde sé, que la no inclusión de este tipo de argumentos en la metodología del

${ }^{29}$ Véanse los artículos compilados en Strawson 1983. Otro ejemplo en relación con la dualidad particular-universal es Strawson 1998b, p. 383. Si el uso de argumentos trascendentales fuera necesario para la realización del análisis conectivo, entonces toda vez que Strawson no utiliza argumentos trascendentales, como en el ejemplo mencionado, no estaría haciendo análisis conectivo, lo cual no es el caso.

${ }^{30}$ Aquí habría que diferenciar entre lo que considero una "actitud trascendental" y "los argumentos trascendentales" propiamente dichos. Es innegable que el análisis conectivo se inscribe en la búsqueda de condiciones necesarias de nuestro pensamiento y experiencia acerca del mundo (esto es, motivaciones metafísicas); sin embargo, no considero que sea privativo de los argumentos trascendentales la tarea propiamente dicha del análisis conectivo de establecer conexiones entre los conceptos.

${ }^{31} \mathrm{Ni}$ siquiera los menciona. Véanse especialmente Strawson 1967 y 1997a. Sólo en Strawson 1985, cap. 1, le dedica unos párrafos para sostener que su función es establecer las conexiones entre los elementos de nuestro esquema conceptual, pero no hay atisbo de que esta función sea constitutiva del análisis conectivo. 
análisis terapéutico (o del reduccionismo quineano) sea una razón de peso para que estas últimas sean una amenaza para el análisis conectivo. ${ }^{32}$

Dado el carácter no constitutivo de los argumentos trascendentales con respecto al método conectivo y dado que la no utilización de argumentos trascendentales por parte de las otras metodologías en cuestión no constituye una amenaza para el desarrollo del análisis conectivo, considero que no hay impedimento en este punto para la compatibilización del análisis terapéutico/conectivo con el análisis conectivo. Por supuesto que entre Strawson y Wittgenstein las diferencias de motivaciones (metafísicas frente a semánticas), objetivos (resolución de problemas filosóficos frente a disolución y tesis metafilosóficas ( $\left(i^{\prime}\right)$ establece una jeraquía entre la filosofía y la ciencia, mientras que (ii") las torna investigaciones no relacionadas jerárquicamente) ${ }^{33}$ siguen en pie. Mi intención no es anular estas diferencias, sino, como ya se ha dicho, mostrar que los rasgos del análisis terapéutico que menciona Strawson no constituyen un peligro para el análisis conectivo.

\section{El análisis conectivo y la concepción reduccionista de la filosofía}

Hemos visto que para Strawson la amenaza del análisis terapéutico radica en su "espíritu negativo y no constructivo (asistemático)" en oposición al "espíritu positivo y constructivo" del análisis conectivo. Ahora bien, según Strawson, del lado de este último polo hay un segundo peligro para el análisis conectivo que consiste en el reduccionismo ontológico de Quine. En primer lugar me ocuparé de reconstruir la polémica ontológica, luego haré algunas observaciones acerca de por qué esta polémica afecta la tarea del análisis conectivo, a continuación retomaré la polémica y ofreceré una manera de entender el naturalismo quineano que no constituiría una amenaza para el análisis conectivo.

\footnotetext{
${ }^{32}$ Cabe hacer notar que, para algunos autores (Grayling 1992, Harrison 1998), Wittgenstein también utiliza argumentos trascendentales para mostrar que hay ciertas creencias que pertenecen a nuestro marco de referencia y que sólo a partir de ellas tienen lugar los juegos del lenguaje y todo conocimiento (véase SC) y cuando argumenta sobre la imposibilidad de un lenguaje privado (véase PI). Sin embargo, en relación con el primer ejemplo, hay pasajes de SC, como los § 114 y § 509, en los que más bien las condiciones de posibilidad no serían trascendentales sino pragmáticas, basadas en la seguridad y confianza en ciertos presupuestos. (Agradezco a Samuel Cabanchik el haberme hecho notar este último punto.) Por otro lado, es interesante señalar que cuando Hacker (1996, cap. 6) compara el análisis conectivo con el terapéutico, no hace mención de la cuestión de los argumentos trascendentales. Pudiera ser una carencia de la comparación, pero creo que indica algo más profundo en dirección de la independencia que intento mostrar.

${ }^{33}$ No me ocupo explícitamente de esta distinción porque no considero que constituya un inconveniente aquí. Tanto $\left(\mathrm{i}^{\prime}\right)$ como $\left(\mathrm{i}^{\prime \prime}\right)$ comparten el aspecto conceptual de la tarea filosófica, y el análisis conectivo/terapéutico propiamente dicho es compatible con la relación jerárquica que establece $\left(\mathrm{i}^{\prime}\right)$.
} 
A fin de comprender la función referencial del lenguaje ordinario, clarificar nuestro esquema conceptual y simplificar las teorías científicas, Quine (1960) encara la tarea de la regimentación del lenguaje natural por medio del aparato de la lógica de predicados de primer orden. La regimentación consiste en la paráfrasis de oraciones del lenguaje ordinario en la notación canónica (predicación, cuantificación y funciones veritativas) de manera que se eliminen nociones oscuras y así se clarifique el esquema conceptual de la ciencia. Una vez que se traduce la teoría a la notación canónica, se utiliza un test para establecer los compromisos ontológicos de esa teoría. Quine (1984) formula su criterio de compromiso ontológico en la famosa frase "ser es ser el valor de una variable", esto quiere decir que una teoría está comprometida ontológicamente con aquellas entidades (el universo de valores) que recorren las variables ligadas de cuantificación. La idea básica es que si la teoría hace afirmaciones de la forma "Todo objeto es tal que..." o "Algún objeto es tal que...", se compromete con los objetos recorridos por esos cuantificadores, de manera que estas afirmaciones son verdaderas sólo si existe un objeto que sea tal y cual o si existe la entidad que tiene la propiedad tal y cual.

Ahora bien, el criterio de compromiso ontológico sólo dice lo que una teoría afirma que hay, no lo que hay. Esto último depende de que la teoría sea verdadera, lo que a su vez depende de qué tipo de entidades admite. Quine formula los cánones de admisibilidad ontológica en la también famosa frase: "no hay entidad sin identidad". Dado que las entidades intensionales (o abstractas) no tienen criterios claros de identidad, no pueden considerarse entidades. ${ }^{34}$ Por ende, estos cánones actúan como filtro para el criterio de compromiso ontológico, porque si una teoría se compromete con entidades abstractas, no es verdadera. Así, para Quine, lo que aceptamos en nuestra ontología son las entidades que son sujetos de predicación (u objetos fundamentales de referencia), y esas entidades son las espaciotemporales (u objetos físicos). De manera que el resultado de la paráfrasis en la concepción quineana es que nos evita comprometernos con entidades no deseadas (las no espacio-temporales) como las entidades abstractas (propiedades, proposiciones, relaciones, etc.). ${ }^{35}$

Es aquí, en la cuestión del rechazo de las entidades abstractas como parte de la ontología, donde Strawson ubica su polémica con Quine. ${ }^{36}$ Strawson se opone en particular a los cánones quineanos de admisibilidad ontológica. Según Strawson, la motivación quineana para sostener un reduccionismo ontológico radica en que sólo cuentan las entidades que la

${ }^{34}$ Cfr. Quine 1990a.

${ }^{35}$ No me es posible desarrollar aquí la propuesta quineana de reemplazo de las entidades intensionales. Véase Quine 1960, cap. 6.

${ }^{36}$ Strawson (1998a) afirma que la polémica con Quine está concentrada en tres artículos: 1990, 1979 y 1976; por ende, enfocaré mi atención particularmente en ellos. 
ciencia dice que hay. Sin embargo, Strawson advierte que en nuestro discurso ordinario tratamos los universales como sujetos de predicación y en ese sentido debemos admitir su existencia.

Antes de seguir desarrollando este punto de fricción entre estas concepciones ontológicas, es necesario comprender por qué esta polémica ontológica amenaza la tarea del análisis conectivo. Para ello habría que hacer dos cosas. Primero, aclarar en qué medida la empresa strawsoniana que parece plantearse en el plano conceptual/lingüístico (al menos el análisis conectivo se aplica a los términos de nuestro esquema conceptual/lingüístico) es afectada por esta polémica en el plano ontológico, y en relación con esto, en qué sentido la postura quineana en el plano ontológico conlleva algún tipo de análisis reductivo.

En cuanto a lo primero, habría que volver sobre las relaciones entre los ámbitos conceptual, lingüístico y ontológico en Strawson y mostrar que forman parte de una empresa filosófica única que cabe bajo el rótulo de análisis conectivo. El análisis conectivo es un método que se aplica en el plano lingüístico simplemente por una cuestión metodológica, pero abarca los otros planos, el conceptual y el ontológico. ${ }^{37}$ Se podría reconstruir el argumento metodológico en favor del plano lingüístico de esta manera:

(i) La teoría general del ser (la ontología), la teoría general del conocimiento (la epistemología) y la teoría general de la proposición, de lo que es verdadero o falso (la lógica), no son sino tres aspectos de una investigación unificada. (Strawson 1997a, p. 80)

(ii) Si hablamos de nuestra estructura conceptual, de la estructura de nuestro pensamiento sobre el mundo, en lugar de hablar, como si dijésemos, del mundo directamente, conservamos un control más firme de nuestro propio proceder filosófico, una comprensión más clara de aquello que nos ocupa. (Strawson 1997a, p. 77)

(iii) Puesto que el pensamiento es demasiado elusivo para ser estudiado excepto en su expresión lingüística, la cuestión del pensamiento de objetos se transforma en una cuestión acerca de la referencia verbal a objetos, y somos arrojados a la filosofía del lenguaje. (Strawson 1990, p. 310)

iv) Por ende, es mejor estudiar el lenguaje.

Ahora bien, lo que Strawson necesita es mostrar la verdad de la premisa (i), porque si no es el caso de (i), entonces, no se sigue ni (ii), ni (iii) ni (iv). Es

${ }^{37}$ También abarca el plano epistemológico. Paralelamente al caso de Wittgenstein, aquí no me ocupo específicamente de este plano (véase la nota 9). Asimismo, desdoblo el plano lógico en los planos conceptual y lingüístico atendiendo al objetivo de mostrar que Strawson y Quine comparten la visión de la interconexión entre estos planos. 
decir, Strawson tiene que mostrar que hay un paralelismo entre los planos ontológico, conceptual y lingüístico para lo que le interesa estudiar: la exhibición de los rasgos estructurales del esquema conceptual en términos del cual pensamos acerca del mundo. Cabe aclarar que, hasta donde sé, no hay un argumento para mostrar el paralelismo entre los planos conceptual y lingüístico; esto no es sorprendente porque es algo que aceptan, al menos, la mayoría de los filósofos analíticos. ${ }^{38}$ Con respecto al paralelismo entre los planos conceptual/lingüístico y ontológico, Strawson ofrece el siguiente argumento:

(i) Reconocemos que hay conceptos y tipos de conceptos de una elevada generalidad que están omnipresentes en nuestro pensamiento y nuestro discurso sobre el mundo. (Strawson 1997a, pp. 77-78)

(ii) En la medida en que se trata de conceptos de clases de cosas, resulta bastante inconcebible que se los use de esta forma omnipresente o universal, a no ser que demos por sentado que hay en el mundo cosas a las que se aplican estos conceptos. (Strawson 1997a, p. 78)

(iii) Por ende, la pregunta: “¿Cuáles son entre nuestros conceptos, o tipos de conceptos, las cosas más generales?” y la pregunta: “¿Cuáles son los tipos más generales de cosas que consideramos que hay o que existen?" en realidad vienen a ser lo mismo. (Strawson 1997a, p. 78)

La premisa (i) parece bastante indiscutible. Strawson sostiene que hay un sentido en el que la premisa (ii) es inofensiva, a saber, que la omnipresencia y generalidad de ciertos conceptos que se utilizan desde el sentido común tiene consecuencias ontológicas en el sentido en que refieren a los tipos de cosas que "pensamos" o "consideramos" que existen. Esta idea no es más que la de los filósofos del sentido común y Strawson es uno de ellos; eso quiere decir que su investigación toma como punto de partida nuestro discurso de sentido común. Por otro lado, Strawson trae en apoyo de (iii) el dato histórico de que filósofos como Aristóteles, Kant, Frege, Russell e incluso Quine creen en una conexión íntima entre estos planos. ${ }^{39}$

Hay un sentido en el que Quine también relaciona el plano conceptual/lingüístico y el ontológico. Uno de los objetivos de la regimentación del lenguaje natural es la clarificación de nuestro esquema conceptual. ${ }^{40}$

${ }^{38}$ La idea no es que pensamiento y lenguaje sean lo mismo; al menos, ningún filósofo razonable de ninguna corriente filosófica sostendría esto. Los planos se asimilan como una estrategia metodológica, tal como se puede ver, antes, en la premisa (iii) del argumento en favor del estudio del lenguaje.

${ }^{39}$ Cfr. Strawson 1997a, p. 82.

${ }^{40}$ Cfr. Quine 1960, p. 158. 
Así, "la búsqueda o el deseo de un esquema general de notación canónica que sea lo más simple y claro posible no puede distinguirse de la búsqueda de categorías últimas, de un retrato de los rasgos más generales de la realidad" (Quine 1960, p. 161). ${ }^{41}$ La cita no alude sólo al formato abstracto de nuestro pensamiento, sino que justamente su doctrina ontológica viene a proporcionar el contenido de las formas que ofrece la notación canónica.

Una vez que está claro que ambos filósofos se mueven en los mismos planos, la disputa pasa al ámbito de la elección del marco conceptual adecuado para describir la realidad. Adoptar el esquema conceptual científico/quineano implicaría una reducción considerable de nuestro esquema conceptual general, porque restringe la naturaleza de la investigación de las relaciones entre los conceptos, dejando de lado los de sentido común. Más aún, la ontología importa a la tarea del análisis conectivo porque, según la concepción que se tenga, podrían eliminarse ciertos conceptos indispensables en nuestro discurso y experiencia acerca del mundo. Volveré sobre esto más adelante.

Ahora, queda por aclarar el segundo punto mencionado anteriormente, esto es, mostrar la relación entre el análisis reductivo y el reduccionismo ontológico. Está claro que la relación no es de implicación. El programa de reducción ontológica de Quine (reducir compromisos ontológicos por medio de la paráfrasis formulada en notación canónica) no implica el análisis reductivo (reducir conceptos complejos a conceptos simples por medio de la descomposición), ni a la inversa. Según Strawson (1997a, p. 92), la relación es de semejanza formal: "ciertos tipos de entidades son fundamentales para la estructura de nuestro pensamiento, porque la necesidad de referirnos a ellos sobreviviría a la presión de la paráfrasis", mientras que otros tipos de entidades estarían de más. Así, la tarea de un análisis reductivo en este sentido no consistiría en llegar a elementos simples, sino en reducir (y eliminar) aquellos conceptos que no soportan la paráfrasis crítica. Dicho en otras palabras, la oposición es a reducir el lenguaje ordinario al lenguaje utilizado por las ciencias. Ése es el tipo de análisis al que se opone Strawson.

Hasta aquí hemos visto que el punto de controversia entre Quine y Strawson acerca de las entidades abstractas se enmarca fundamentalmente en la oposición ciencia-filosofía/sentido común (tesis metafilosófica (i')) cuya otra cara es la oposición lenguaje regimentado-lenguaje ordinario (tesis metafilosófica (ii')). Strawson ve a Quine como alguien que sólo acepta el esquema conceptual ofrecido por la ciencia (recuérdese que la regimentación del lenguaje ordinario, y su criterio de compromiso ontológico y los

${ }^{41}$ Palabra y objeto, p. 171. Hay otro pasaje de Quine (1984, p. 36) en el que se ve claramente la relación entre los planos lógico, ontológico y epistemológico: "la ontología de cada cual es básica para el esquema conceptual mediante el cual interpreta todas las experiencias, incluso las más tópicas". 
cánones de admisibilidad ontológica están dirigidos a las teorías científicas) y de esa manera deja de lado lo que Strawson sostiene que le interesa a la filosofía, que es el esquema conceptual de sentido común. Éste es el esquema conceptual del cual habla Strawson, la filosofía se ocupa de aquellos conceptos del "pensamiento menos refinado" y de los cuales dependen los conceptos teóricos de las disciplinas científicas, en el sentido de que la habilidad para usar estos últimos depende de la habilidad para usar aquellos conceptos del discurso no técnico, ordinario (los conceptos básicos). Así, la regimentación lógica del lenguaje ordinario a los fines de la clarificación del esquema conceptual de la ciencia constituye una amenaza para la tarea filosófica del análisis conectivo de los conceptos que constituyen nuestro discurso y nuestra experiencia de sentido común.

Para mostrar que la ontología quineana no comporta el peligro que Strawson ve en ella para el análisis conectivo, habría que mostrar que Quine no niega la existencia de aquello que no se acomoda a la ontología de la ciencia natural; en otras palabras, que la concepción filosófica de Quine no deja de lado el sentido común (y con ello el lenguaje ordinario). Por supuesto, insisto, si logro este cometido, esto no querría decir que no haya diferencias entre las concepciones de la filosofía de ambos, tan sólo mostraría que la concepción quineana no amenaza el análisis conectivo de la manera "fuerte" en que Strawson lo cree.

Habíamos dejado la polémica en torno a las entidades abstractas en el punto en que Strawson se oponía en particular a los cánones quineanos de admisibilidad ontológica. Strawson sostiene que en nuestro discurso ordinario tratamos los universales como sujetos de predicación y no por ello nos comprometemos con "no entidades". ${ }^{42} \mathrm{El}$ argumento fundamental para admitir entidades abstractas en la ontología consiste en que dado que los universales pueden ser objetos de referencia en nuestro discurso ordinario, y dada la conexión entre ser un objeto de referencia y ser una entidad, entonces hay que admitir este tipo de objetos en nuestra ontología. ${ }^{43} \mathrm{El}$ único criterio que se requiere para que algo forme parte de nuestra ontología (ser un objeto genuino de referencia) es que pueda ser identificado como la cosa que es (aquí la frase famosa es: "toda entia debe ser identifiabilia"). ${ }^{44}$

\footnotetext{
${ }^{42}$ La expresión 'no entidades' es la que utiliza Strawson 1990, p. 317.

${ }^{43}$ Cfr. Strawson 1998a.

${ }^{44}$ Cfr. Strawson 1990, p. 314. Si el test de admisibilidad quineano quiere decir que sólo son entidades aquellas para las cuales hay un criterio general de individuación para todas las cosas que forman parte de un mismo tipo, entonces, el test es falso porque en el caso de los universales no se requiere un criterio general de individuación. Strawson (1976, p. 23) afirma: "el criterio de aplicación del predicado es el criterio individual de identidad de la cualidad o relación individual. El sentido del término general da la esencia individual de la cosa general. Por eso, no hay necesidad de criterios de identidad generales para cosas de la clase a la cual pertenecen las cosas generales." Así, captar el sentido de un predicado es captar
} 
No sólo en nuestro discurso ordinario tratamos como sujetos de predicación a entidades abstractas, de manera que las "entidades son simplemente las cosas identificables, generales o particulares, que necesitamos reconocer en la práctica como soportes de predicación" (Strawson 1990, p. 317), sino que la habilidad para reconocer un particular depende de la habilidad para reconocer universales. Strawson (1959) se compromete con ciertas entidades que denomina particulares (individuos espaciotemporales) básicos. Los particulares básicos son los elementos recorridos por las variables de cuantificación de Quine. ${ }^{45}$ De entre los particulares, los cuerpos materiales son los básicos porque constituyen nuestro esquema conceptual en el sentido de que le otorgan sus propias características (la tridimensionalidad, la duración en el tiempo y la accesibilidad a medios de observación). ${ }^{46}$ Nuestro esquema conceptual es un sistema de relaciones espacio-temporales entre los cuerpos materiales que tienen su lugar en él. Así, cada entidad es identificada en función de su lugar en el sistema o a partir de una entidad que tiene su lugar en el sistema.

Sin embargo, nuestro pensamiento ordinario y nuestra experiencia cotidiana de objetos naturales no sería posible si no existieran las entidades abstractas:

no podemos pensar en cualquier cosa natural, o, en un sentido pleno, percibirla, ya sea un objeto o evento, sin pensarla, o percibirla, bajo algún aspecto general: como siendo así y asá o tal o cual; como si tuviera algún carácter general o fuera de una clase general. La generalidad y la particularidad son de igual modo rasgos necesarios y mutuamente dependientes de nuestra experiencia así como de nuestra habla. (Strawson 1979, p. 59)

Así, en paralelo con el marco conceptual conformado por los particulares, los universales (o entidades abstractas) conforman un marco definido en términos de relaciones lógicas (inclusión/exclusión, orden jerárquico, etc.). Mientras que los particulares están en un espacio físico (son "objetos particulares en la naturaleza" y objetos del pensamiento), los universales están organizados en un espacio lógico (son sólo "objetos abstractos del pensamiento"). ${ }^{47}$

el principio de identidad de la propiedad. Y captar sentidos (o significados) es lo que hacemos cuando dominamos un lenguaje.

${ }^{45}$ Cfr. Strawson 1997a, p. 103.

${ }^{46}$ Cfr. Strawson 1959, p. 39.

${ }^{47}$ Cfr. Tse 1998. Los universales no tienen existencia independiente (no se trata de un realismo platónico) ni se reducen a agregados de particulares (no se trata de un nominalismo). Reconocer un universal (por ejemplo, que algo es un árbol) no requiere reconocer algo adicional (el universal árbol), sino sólo sus ejemplares. La relación entre el universal y sus ejemplares es de ejemplificación y es una relación no natural (esto es, no está en la naturaleza) al igual que las relaciones no naturales entre los universales tal como la necesidad conceptual (lógica 
El tema de las entidades abstractas no es más que uno de los rasgos del sentido común que el marco conceptual de la ciencia deja de lado. Strawson (1985) sostiene que si se parte del marco conceptual científico y sólo se aceptan las entidades que la ciencia (en particular, la física) dice que hay, entonces nuestra ontología se ve vaciada de la experiencia fenoménica y las actitudes morales. No me voy a ocupar de esto, pues creo que con la polémica acerca de las entidades abstractas se muestra de manera suficiente la motivación que lleva a Strawson a combatir cualquier imposición de un esquema conceptual que deje fuera cualquier rasgo de sentido común, ya sea el pensamiento ordinario o nuestra experiencia cotidiana. ${ }^{48}$ Con el criterio strawsoniano de admisibilidad ontológica (a diferencia del criterio quineano de "no hay entidad sin identidad"), queda asegurado que el esquema conceptual de sentido común no quede fuera de nuestra concepción del mundo y, así, que sea posible tener una ontología "tolerante".

Según hemos visto, para Quine, en las teorías científicas los objetos fundamentales de referencia (o, en otras palabras, los elementos recorridos por las variables de cuantificación) son los objetos físicos entendidos como "el contenido material de cualquier porción de espacio-tiempo, por más irregular, discontinua y heterogénea que sea" (1981, p. 10). Hay varias motivaciones en favor del compromiso ontológico con los objetos físicos; una de ellas consiste en que tenemos evidencia empírica de ellos a través de las "irritaciones de nuestra superficie", esto es, a través de los estímulos sensoriales. Además, los objetos físicos tienen un criterio de identidad que consiste en la coextensividad (dos objetos son idénticos si y sólo si son coextensivos). Quine los considera un postulado, un constructo teórico, en la medida en que la ciencia los necesita para llevar a cabo su tarea. ${ }^{49} \mathrm{En}$ este sentido, Quine acepta ciertas entidades abstractas necesarias para la ciencia; por ejemplo, las clases (y los números), porque tienen un criterio claro de individuación (son idénticas si sus miembros lo son). Como el resto de las entidades abstractas no tienen un criterio claro de individuación, son rechazadas del esquema conceptual científico.

o semántica o analítica). Si bien Strawson no admite que haya dos sentidos de existencia, uno para los particulares y otro para los universales, hay una diferencia en las implicaciones de existencia de ambas entidades. La existencia de particulares implica la "posesión real de una localización espacio-temporal", mientras que la de los universales implica la "posibilidad lógica" de sus intancias (Cfr. Strawson 1998c).

${ }^{48}$ Es interesante hacer notar que en Strawson 1985 se considera a Wittgenstein como el interlocutor principal del naturalismo reduccionista con respecto a las entidades abstractas y no, como se podría esperar, a Quine.

${ }^{49}$ En un sentido, para Quine, toda nuestra ontología no es más que lo que postulamos que tiene que existir, porque esas entidades son teóricamente indispensables para construir las teorías científicas. "Todo a lo que le concedemos existencia es algo que postulamos desde el punto de vista de una descripción del proceso de construcción de una teoría" (Quine 1960, p. 22). 
Mientras que Quine, según Strawson (1985), es un naturalista reduccionista ya que considera que la (exclusiva) concepción de lo real se reduce a lo que la ciencia natural dice que hay (lo que sea que esté en la naturaleza), el naturalismo tolerante de Strawson (1985) admite distintas concepciones de la realidad. Estas concepciones consistirían básicamente en dos: la científica y la del sentido común. En tanto que en la primera las entidades abstractas quedan eliminadas, en la segunda éstas cumplen un papel primordial en la fundamentación metafísica y epistemológica de los rasgos de nuestro esquema conceptual ordinario. La concepción científica quineana, al no aceptar las entidades abstractas como parte de la ontología, no reconoce en particular la fundamentación metafísica (la dualidad particular-universal) de la dualidad lógica.

Ahora bien, es aquí donde está el punto fundamental de la polémica y donde Strawson, me parece, advierte ciertos aspectos del naturalismo de Quine, pero no profundiza en ellos, con lo cual su concepción del naturalismo quineano es parcial. ${ }^{50}$ Lo que Quine sostiene es que ciertas clases de entidades (que Strawson considera que forman parte del sentido común) no forman parte de la ciencia natural; no está negando la existencia de lo que no cuadra en su ontología. Strawson mismo lo admite cuando afirma que "Quine no niega de manera absoluta la existencia de todo lo que no se acomoda en su ontología elegida. Por ejemplo, su materialismo no es la negación de lo mental [...]; más bien es la afirmación de que la comprensión ordinaria no satisface los requisitos rigurosos de la comprensión científica." ${ }^{11}$ Es aquí donde creo que radica la diferencia de motivaciones, Strawson cree que la ontología quineana es una amenaza a la empresa del análisis conectivo porque Quine sostiene que la única fuente de comprensión del mundo es la ciencia natural, dejando de lado así la comprensión ordinaria del mundo. Sin embargo, no creo que sea eso lo que sostiene Quine. Veamos en qué sentido el naturalismo quineano no deja de lado el sentido común (y con ello el lenguaje natural) en la empresa mayor de nuestra comprensión del mundo. Para ello hay que concentrarse en otra famosa frase quineana: "la filosofía es continua con la ciencia".

Según Haack (1998), es posible distinguir tres tesis en el naturalismo de Quine. Una es la tesis de la continuidad entre la ciencia y la filosofía (tanto la filosofía como la ciencia forman un continuo que conforma nuestro conocimiento empírico); otra es la tesis cientificista (la filosofía es parte de la

${ }^{50}$ Esto no es algo que se le pueda atribuir sólo a Strawson, quien no hace más que centrarse en la interpretación heredada de la concepción quineana.

${ }^{51}$ Strawson 1990, p. 312; las cursivas son mías. En este sentido, para Quine, las entidades abstractas no son sólo irreducibles sino que, por ejemplo en el caso de las intencionales, éstas son indispensables para nuestro marco conceptual (no científico), de manera que no hay que buscar una unificación teórica de los relatos físico y mental. Véanse Quine 1990b, p. 72, y Haack 1998. 
ciencia). Según Haack, estas tesis son incompatibles porque la filosofía no puede ser continua con la ciencia y al mismo tiempo ser asimilada a ella. Este conflicto se debe a la ambigüedad con que Quine utiliza el término 'ciencia': a veces lo emplea de manera estrecha para refererise a la ciencia natural y a veces lo usa de manera amplia para referirse al conocimiento empírico en general. Por eso hay que entender la tesis cientificista como si dijera que la filosofía forma parte del conocimiento empírico (y no de la ciencia natural). Por otro lado, una tercera tesis que conforma su naturalismo es la tesis de la extensionalidad (producto de su criterio de admisibilidad de entidades). Si bien esta tesis es independiente de la tesis de la continuidad, afecta la manera de entenderla. Sin embargo, dado que Quine (1990b, p. 72) afirma que la extensionalidad no es parte de su concepción de la ciencia como tal, es posible mantenerla a un lado y de esta forma entender el naturalismo de Quine de una manera mucho menos fuerte que como Strawson lo entiende. ${ }^{52}$

Siguiendo estas distinciones, y teniendo en cuenta que Haack (1997) incluye el sentido común dentro del conocimiento empírico general, uno debería entender el naturalismo quineano como la continuidad entre tres tipos de conocimientos: el filosófico, el científico y el de sentido común. ${ }^{53}$ Ahora bien, la continuidad no implica identidad y en ese sentido no hay manera en que alguno de esos conocimientos sea reducido al otro; es el conjunto del conocimiento humano el que se pone a prueba. Por ende, en lo que no se distinguen estos tipos de conocimiento es en la posibilidad de revisarlos. En este sentido, nuestros distintos tipos de conocimientos forman parte de una misma empresa que es la del conocimiento humano. Quine lo expresa de esta manera:

mi posición es una posición naturalista; veo la filosofía no como una propedéutica a priori o como los preliminares para la ciencia, sino como algo continuo con la ciencia. Veo la filosofía y la ciencia en el mismo bote; un bote que, volviendo a la figura de Neurath como a menudo hago, podemos reconstruir sólo en el mar mientras flotamos en él. (Quine 1967, pp. 126-127)

Así, siguiendo la propuesta de Haack sobre el sentido común, éste no quedaría fuera de la empresa mayor del conocimiento humano y, en ese sentido, la postura quineana no es un peligro para el análisis conectivo. Se

${ }^{52}$ Cfr. Haack 1998 sobre la independencia de la tesis extensionalista con respecto a la de la continuidad.

${ }^{53}$ En Pérez (1999) también se sostiene esta interpretación del naturalismo quineano. Por otro lado, la ubicación del sentido común y la filosofía dentro del conocimiento empírico general constituiría un obstáculo insuperable para que el análisis conectivo tuviera su lugar; sin embargo, veremos más adelante que esta empresa del conocimiento humano incorpora elementos conceptuales. Por otro lado, en lo que sigue no haré una distinción entre los ámbitos del sentido común y la filosofía, dado que en Strawson ambos se entremezclan. 
pueden seguir estableciendo las conexiones entre los conceptos en esta red amplia que constituye la empresa del conocimiento humano. ${ }^{54}$

Ahora bien, como lo que está en juego es el conjunto del conocimiento humano, se podría pensar que las distintas posturas en torno a la polémica con respecto a los criterios de admisibilidad ontológica podrían acomodarse en distintos sectores de esta empresa total. Así, para la ciencia se podrían aceptar los cánones quineanos, mientras que para la filosofía/sentido común, los cánones strawsonianos. De hecho, Strawson (1985, 1997a) considera que los puntos de vista científico y del sentido común/filosofía contituyen la imagen total del mundo y que la elección de cuál adoptar depende del esquema conceptual que nos permita movernos mejor según el entorno: si es el de la ciencia será el quineano; si es el del sentido común será el strawsoniano. A lo único que se opone Strawson (1985) es a la idea de que es la ciencia la que nos da la exclusiva y correcta concepción de la realidad. Pero, según la tesis de la continuidad, no se supone que alguna perspectiva que participa en la empresa total del conocimiento tenga preponderancia sobre la otra.

Sin embargo, pese a esta actitud tolerante de Strawson hay una tensión entre los puntos de vista de la ciencia y la filosofía/sentido común por sus tesis metafilosóficas. Según (i'), la tarea de la filosofía es puramente conceptual y es más básica conceptualmente con respecto a la ciencia. Según (ii'), el lenguaje ordinario tiene todos los recursos necesarios para una comprensión ordinaria y filosófica. Con respecto a (ii'), no está claro que Strawson esté en desacuerdo con la idea de que el lenguaje natural no cumple con los requisitos del entendimiento científico; más bien lo que se hace en Strawson (1985) es plantear los puntos de vista científico y del sentido común sin intentar sostener que es posible desechar el primero o reducirlo al segundo. El objetivo de Strawson allí es sólo establecer que el punto de vista del sentido común es irrenunciable, cuestión que queda asegurada con la interpretación del naturalismo quineano ofrecida.

Con respecto a $\left(i^{\prime}\right)$, la tesis de la continuidad no excluye el establecimiento de relaciones conceptuales. Este punto depende de cómo se entienda el rechazo quineano de la distinción analítico-sintética. Desarrollarlo requeriría un trabajo aparte; pero se puede decir que si uno entiende dicho rechazo en el sentido de que la distinción es una cuestión de grado y que aquello que consideramos analítico es lo que no estamos dispuestos a sacrificar ante la revisión de nuestros conocimientos, ${ }^{55}$ esto es perfectamente compatible con la idea strawsoniana de que hay ciertas creencias que for-

\footnotetext{
${ }^{54}$ Strawson no avalaría la tesis de la continuidad, pero ése no es un problema porque no se está intentando asimilar los naturalismos de Quine y Strawson; lo único que se pretende mostrar es que si se entiende la concepción quineana de una manera menos fuerte que como la entiende Strawson, ésta no constituiría una amenaza para la empresa del análisis conectivo.

${ }^{55}$ Véase Quine 1973 en relación con la no revisión de las verdades lógicas, y Quine 1987,
} 
man parte de nuestros compromisos irrenunciables. ${ }^{56}$ En este sentido, la tesis de la continuidad da cabida a que el conocimiento humano esté conformado tanto por un aspecto empírico como por otro conceptual. ${ }^{57}$ Con respecto a la idea de que los conceptos de sentido común son más básicos que los conceptos científicos, creo que esto no constituye ningún tipo de predominio real de la filosofía, más bien es una descripción empírica basada en evidencia evolutiva. De hecho, los conceptos científicos son conceptos de adquisición tardía tanto en la ontogénesis como en la filogénesis. Finalmente, la tesis (iii) acerca de la utilización de argumentos trascendentales no constituye un obstáculo para que el análisis conectivo tenga un lugar en esta interpretación del naturalismo quineano, dado que hemos visto que la utilización de argumentos trascendentales no es constitutiva del análisis conectivo.

Lo que intenté mostrar en este apartado es que lo que lleva a Strawson a combatir la concepción quineana de la filosofía es el rechazo de cualquier imposición de un esquema conceptual que deje fuera cualquier rasgo de sentido común. Sin embargo, no parece ser ése el objetivo de Quine al enunciar su tesis de la continuidad. De manera que, al quedar resguardado el sentido común, la concepción quineana no constituiría en este aspecto una amenaza para el análisis conectivo.

\section{Conclusión}

Strawson entre Wittgenstein y Quine significa, para Strawson, el análisis conectivo entre dos peligros, a la izquierda el espíritu negativo y la asistematicidad, y a la derecha la intolerancia ontológica. Me propuse mostrar aquí que no hay tales amenazas si uno interpreta el análisis terapéutico y la empresa quineana en un sentido más "tolerante". Así, intenté mostrar, por un lado, que el "espíritu negativo" es una cuestión de actitud que no influye significativamente en el resultado del análisis, que consiste en una "visión clara" de las relaciones entre nuestros conceptos, al igual que el del análisis conectivo; y, por el otro, que el análisis terapéutico/conectivo es compatible con la sistematicidad. Con respecto al peligro de la intolerancia ontológica, quise mostrar que el hecho de que la tesis quineana de la

donde afirma que el énfasis en contra de la noción de analiticidad apuntaba a su propósito epistemológico.

${ }^{56}$ Cfr. Strawson 1985, cap. 1. Sin embargo, véase Grice y Strawson 1956 para una defensa de la distinción. Por supuesto, las motivaciones para la no revisión son pragmáticas en el caso de Quine y metafísicas en el de Strawson.

${ }^{57}$ En dicho sentido, tanto en la ciencia como en la filosofía/sentido común habría elementos conceptuales y empíricos. Strawson no estaría de acuerdo con la idea de que en la filosofía hay elementos empíricos (Cfr. Strawson 1998d, p. 65). Sin embargo, esta diferencia metafilosófica no es un inconveniente. Todo el punto es que mientras haya elementos conceptuales, el análisis conectivo tiene cabida. 
continuidad entre la filosofía y la ciencia no deja de lado el sentido común permite la tarea del análisis conectivo y, en este sentido, la concepción quineana no constituiría una amenaza para este análisis. Por supuesto, si he logrado mi objetivo, estos rasgos diferentes del análisis conectivo, y que parecerían una amenaza para él, ya no serían un peligro aunque sí mantendrían intacto el calificativo de diferentes.

\section{BIBLIOGRAFÍA}

Dummett, M. , 1990, “¿Puede y debe ser sistemática la filosofia analítica?”, en La verdad y otros enigmas, México, FCE, pp. 534-356.

Grayling A.C., 1992, “Trascendental Arguments”, en J. Ancy y E. Sosa (comps.), A Companion to Epistemology, Oxford, Blackwell.

Grice, H.P y P.F. Strawson, 1956, "In Defense of a Dogma", Philosophical Review, vol. 65, pp. 141-158.

Haack, S., 1998, "Between the Scylla of Scientism and the Charybdis of Apriorism", en Hahn 1998, pp. 49-63.

—_, 1997, Evidencia e investigación. Hacia la reconstrucción en epistemología, Madrid, Tecnos.

Hacker, P.M.S., 1996, Wittgenstein's Place in Twenthieth-Century Analytic Philosophy, Blackwell, Oxford.

Hahn, L. (comp.), 1988, The Philosophy of P.F. Strawson, Peru, Ill. (The Library of Living Philosophers)

Harrison R., 1998, "Trascendental Arguments", en Routledge Encyclopedia of Philosophy, Routledge, Londres.

Pérez, D., 1999, "Acerca del impacto del naturalismo en la filosofía de la mente contemporánea", Análisis filosófico, vol. 19, no. 1, pp. 31-45.

Quine, W.V.O., 1990a, “Comment on Strawson”, en Robert Barrett y Roger Gibson (comps.), Perspectives on Quine, Blackwell, Oxford, pp. 319-320.

— 1990b, The Pursuit of Truth, Harvard University Press, Cambridge, Mass.

—_, 1987, "Respuesta a García", en J.J. Acero y T. Calvo Martínez (comps.), Symposium Quine, Universidad de Granada, Granada, pp. 35-36.

__ 1984, "Acerca de lo que hay", en Desde un punto de vista lógico, Hyspamerica, Buenos Aires, pp. 25-47.

_ , 1981, Theories and Things, Harvard University Press, Cambridge.

—, 1973 , Filosofía de la lógica, Alianza, Madrid.

__, 1967, "Natural Kinds", Ontological Relativity and Other Essays, Columbia University Press, New York.

__ 1960, Word and Object, The MIT Press, Cambridge, Mass. [Versión en castellano: Palabra y objeto, trad. Manuel Sacristán, Labor, Barcelona, 1968.]

Strawson, P.F., 1998a, "Intellectual Autobiography", en Hahn 1998, pp. 3-21.

— , 1998b, "Reply to Chung M. Tse", en Hahn 1998, pp. 383-384.

_ 1998 c, "Reply to Arindam Chakrabarti", en L. Hahn (comp.), 1998, pp. 324327.

_ - 1998d, "Reply to Susan Haack", en Hahn 1998, pp. 64-67.

__, 1997a, Análisis y metafísica, trad. Nieves Guasch, Paidós, Barcelona. 
Strawson, P.F., 1997b, Entity and Identity and Other Essays, Clarendon Press, Oxford. _ _ 1990, "Two Conceptions of Philosophy", en R. Barrett y R. Gibson (comps.), Perspectives on Quine, Blackwell, Oxford, pp. 311-318.

_-, 1985, Skepticism and Naturalism: Some Varieties, Methuen, Londres.

—_, 1983, Ensayos lógico-lingüísticos, Tecnos, Madrid.

_

—, 1976 , "Entity and Identity", en Strawson 1997b, pp. 21-51.

— - 1967, "Analysis, Science, and Metaphysics", en R. Rorty (comp.), 1967, The Linguistic Turn, University of Chicago Press, Chicago, pp. 312-330.

_ 1966 , The Bounds of Sense, Methuen, Londres.

—_, 1961, “Términos singulares y predicación”, en Strawson 1983, pp. 67-89.

— 1959 , Individuals, Methuen, Londres.

Stroud, B., 1968, "Trascendental Arguments", The Journal of Philosophy, vol. 65, no. 9, pp. 241-256.

Tse, C., 1998, "Strawson's Metaphysical Theory of Subject and Predicate", en Hahn 1998, pp. 373-382.

Wittgenstein, L., (GF), 1992, Gramática filosófica, trad. Felipe Segura, Instituto de Investigaciones Filosóficas-UNAM, 1992.

__, 1989, (CAM), Los cuadernos azul y marrón, trad. Francisco García Guillén Tecnos, Madrid.

__ , 1988, (SC), Sobre la certeza, trad. Josep Lluís Prades y Vincent Raga, Gedisa, Barcelona.

—_, 1958, (PI), Philosophical Investigations, Macmillan, Nueva York. [Versión en castellano: Investigaciones filosóficas, trad. Alfonso García Suárez y Ulises Moulines, Instituto de Investigaciones Filosóficas-UNAM, 2003.]

Recibido el 1 de julio de 2002; revisado el 7 de abril de 2003; aceptado el 6 de mayo de 2003 